\title{
Artificial Neural Networks based Approach for Predicting LVDT Output Characteristics
}

\author{
Ashwani Kharola \\ Assistant Professor, Department of Mechanical Engineering, Tula's Institute, Dehradun-248197, India
}

Received: 27 March 2018; Accepted: 16 May 2018; Published: 08 July 2018

\begin{abstract}
This paper presents a novel approach for training and output prediction of data of a Linear variable differential transformer (LVDT). LVDT is a commonly used device used in laboratories for measuring linear displacements in specific situations. This article considers application of Artificial Neural Networks (ANNs) for learning and output estimation of LVDT. Real-time experiments were conducted and results were collected for training of ANNs. The Regression results and outputs verified the learning and prediction capability of ANNs.
\end{abstract}

Index Terms: Artificial neural network, LVDT, Matlab, Simulink, Mean square error, Regression.

(C) 2018 Published by MECS Publisher. Selection and/or peer review under responsibility of the Research Association of Modern Education and Computer Science.

\section{Introduction}

A Linear variable differential transformer (LVDT) is an electromechanical transducer which is capable of measuring very small linear movements [1]. The transducer converts mechanical motion of the system into electrical signals which can be easily recorded and analysed [2]. LVDT can be considered as a differential transformer having one primary coil and two secondary coils connected such that the induced voltages are $180^{\circ}$ out of phase [3]. The assembly comprises of a cylindrical core which can move linearly between the two coils. The output signal produced indicates direction of core movements from the centre position [4]. These devices have capabilities of contact-less sensing, tolerance against radiations, infinite resolution, good linearity and are cost effective [5]. Researchers have been showing keen interest in studying and analysing performance of LVDT's due to their vast engineering applications. In a multi-objective study by Santhosh \& Roy [6], the authors aimed at extending the linear range of LVDT alongwith eliminating its dependency on physical parameters and working temperature. The study further added an artificial neural network block in cascade for

* Corresponding author. Tel.:7248341821

E-mail address: kharola.ashwani@tulas.edu.in 
data conversion. Liu et al. [7] constructed an on-machine learning measuring system having an air-bearing capacitive LVDT contact sensor mounted on a desktop machine tool. The proposed system was capable of decoding the digital signals of linear encoders and also acquires the analog signal of contact sensor. In an article by Meydan \& Healey [8] a linear variable transducer having a metallic glass ribbon as the core material rather than nickel-iron material has been used. The authors investigated the suitability of metallic glass ribbon over other conventional material in terms of excitation magnitude and frequency. Tian et al. [9] proposed an equivalent magnetic circuit for a solenoid type LVDT. The authors considered magnetic circuit theory to calculate its magnetic reluctance, mutual inductance, output voltage and sensitivity. Muhammad \& Umar [10] developed a small scale LVDT to detect level of different fluids. The fluids which were considered for analysis were water, petroleum and gasoline. The results showed that transducers works with good precision and has high sensitivity for all three fluids.

\section{Nomenclature}

ANN Artificial neural network

LVDT Linear variable differential transformer

\section{System Description}

The setup includes a LVDT mounted on a panel provided with a capability of fine movement of core with the help of a lead screw. The lead screw is further coupled with a dial gauge with the help of a thumb and wheel arrangement as shown in Fig.1. The setup includes a low noise carrier frequency signal amplifier of 5 $\mathrm{KHz}$, a demodulator, 3.5 inch digital LED indicator and an I.C. regulated power supply housed in a wooden box. A complete set of system specification are highlighted in Table 1. The circuit diagram of LVDT setup is shown in Fig.2.

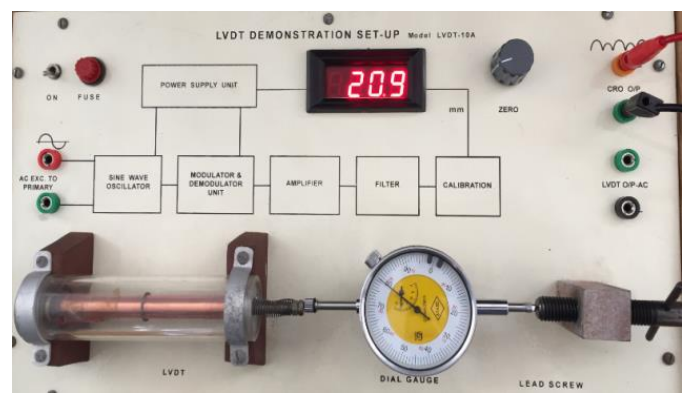

Fig.1. LVDT Setup

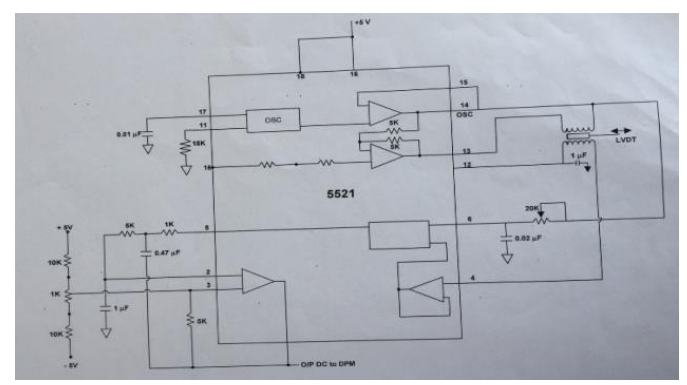

Fig.2. Circuit diagram of LVDT Setup 
Table 1. Specifications of LVDT Setup

\begin{tabular}{cc}
\hline Specification & value \\
\hline Core displacement & $+/-10 \mathrm{~mm}$ \\
Carrier frequency & $5 \mathrm{KHz}$ \\
Carrier voltage & 1.0 Volt r.m.s \\
LVDT output & $190 \mathrm{mVolt}$ \\
Demodulator output & $1.5 \mathrm{Volt} \mathrm{D.C.}$ \\
Power & 220 Volt $/ 50 \mathrm{~Hz}$ \\
\hline
\end{tabular}

The study considered the data samples collected by real-time experiments. The results are obtained by rotating the lead screw through $1 \mathrm{~mm}$ each time and noting down the modulated output voltage. A set of 25 such reading were obtained and stored in .MAT file for further training of Artificial neural networks (ANNs).

\section{Application of ANN for Output Prediction}

Neural networks are computational models which are inspired by biological neurons present in human brain and are used for processing information [11-12]. These networks are widely used in machine learning, speech recognition, computer vision, medicines, text processing processes [13-18]. A basic architecture of ANN is shown in Fig.3. ANN architecture comprises of various nodes and biases whose weights can be adjusted during the learning process. The system comprises of three different layers namely input layer, hidden layer and output layer. All the inputs are fed to the network through input layer. These inputs are processed in the hidden layers and further supplied to output layer as output [19].

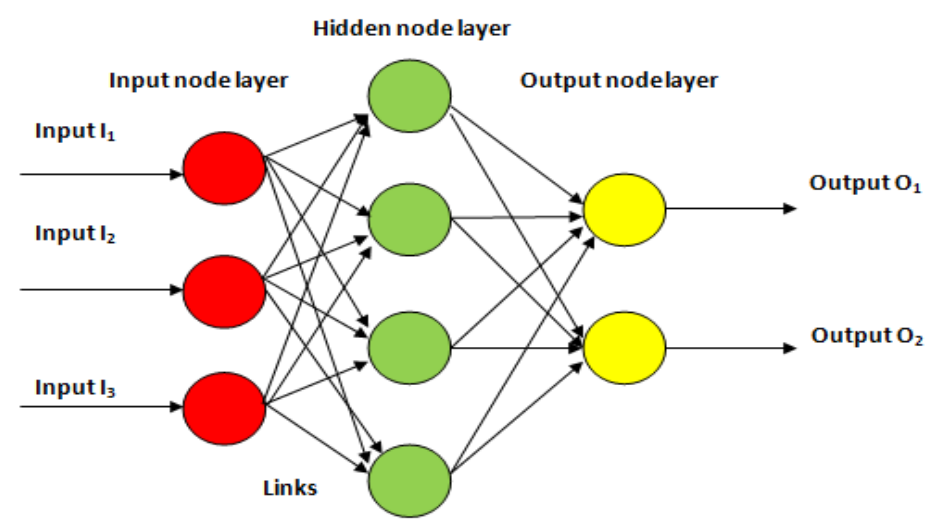

Fig.3. ANN Architecture

The training of ANNs was performed using 25 data samples collected from real-time results of LVDT. These samples were then randomly divided into training, validation and testing samples [20-21]. The training samples aids in tuning of network whereas validation samples were used for measuring network generalization and halts training as generalization stops improving. The testing samples have no effect on training and provide an independent measure of network performance during and after training. The number of neurons considered in hidden and output layer considered was 10 and 1 respectively [22]. A view of neural network architecture consisting of 4-inputs and 1-output is shown in Fig.4. 


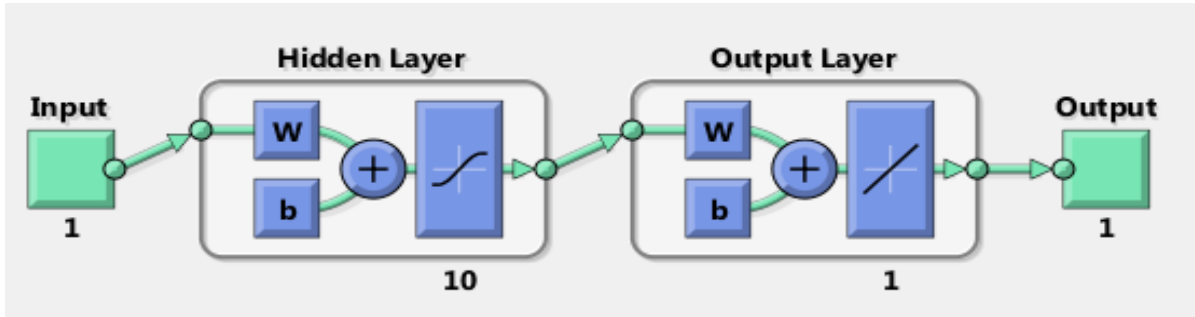

Fig.4. ANN having 4-inputs and 1-output

The network was trained using Levenberg-Marquardt learning algorithm which takes more memory and less time for computation [23]. The number of data samples taken for analysis, Mean Squared Error (MSE) and Regression (R) values obtained after training are shown in Table 2. MSE is the average squared difference between outputs and targets. Lower values of MSE are better whereas zero indicates no error. Regression values are used for measuring the correlation between outputs and targets. $R$ value of 1 means close relationship whereas 0 means random relationship [24]. Training of samples different times yields different results due to different initial conditions and samplings. Training of samples is carried via 1000 iterations and 6 validation checks were performed to obtain optimal results.

Table 2. MSE and R Values Obtained for Different Samples

\begin{tabular}{cccc}
\hline Sample & Number of samples & MSE & R \\
\hline Training & 17 & $2.94882 \mathrm{e}-8$ & $9.9999 \mathrm{e}-1$ \\
Validation & 4 & $3.07529 \mathrm{e}-2$ & $9.9997 \mathrm{e}-1$ \\
Testing & 4 & $2.68479 \mathrm{e}-4$ & $9.9998 \mathrm{e}-1$ \\
\hline
\end{tabular}

The function fit obtained for outputs, targets and errors for different samples is shown with the help of Fig.5.

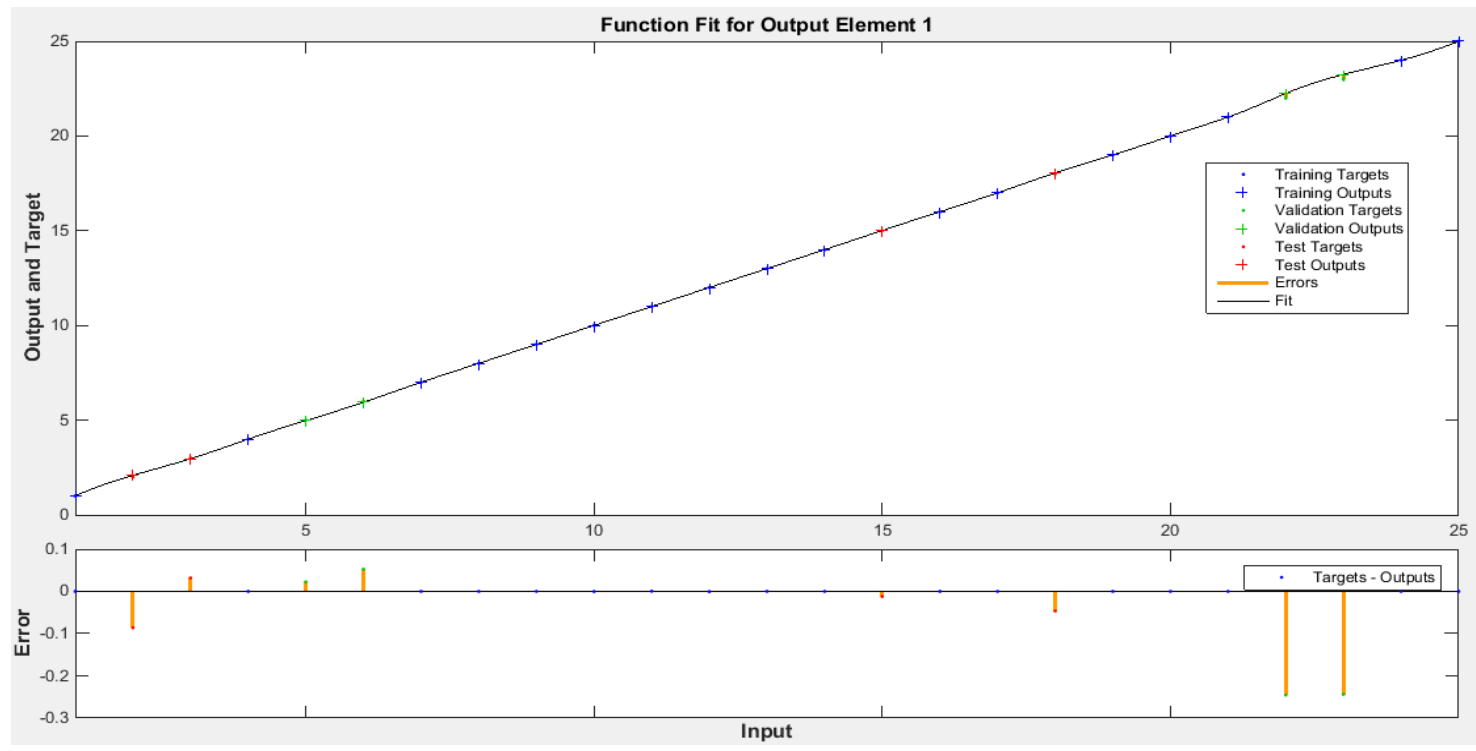

Fig.5. Function Fit Obtained for Different Samples 
The Regression fit obtained for different samples are shown in Fig.6. It is clear from the figure that training and validation samples shows $R$ value of 1 whereas testing samples gives $R$ value of 0.99998 . The $R$ value obtained for all samples is 0.99996 .
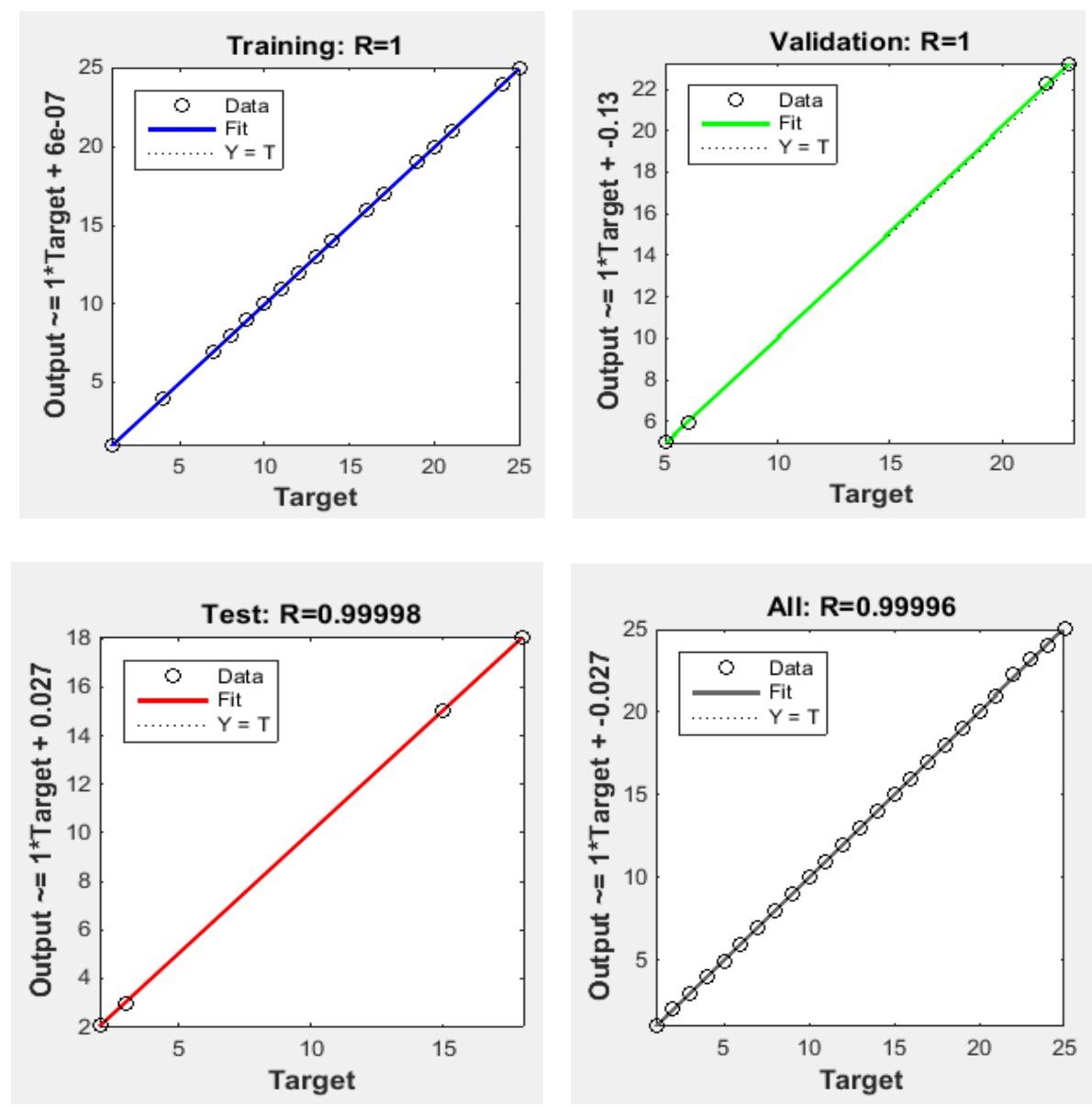

Fig.6. R-plots Obtained for all Samples

A complete detail of number of epochs, time taken for training, performance of network, gradient, validation checks etc are shown with the help of Figure 7. It is clear from the figure that network is trained after 13 iterations and 6 validation checks.

\begin{tabular}{|c|c|c|c|}
\hline Epoch: & 0 & 13 iterations & 1000 \\
\hline Time: & & $0: 00: 02$ & \\
\hline Performance: & $1.56 \mathrm{e}+03$ & 3.85 & 0.00 \\
\hline Gradient: & $4.97 e+03$ & 5.11 & $1.00 \mathrm{e}-07$ \\
\hline Mu: & 0.00100 & 0.0100 & $1.00 \mathrm{e}+10$ \\
\hline Validation Checks: & 0 & 6 & 6 \\
\hline
\end{tabular}

Fig.7. Performance Results Obtained for ANNs 
After completion of training a Simulink-model of above system has been generated as shown in Fig.8. The results of Simulink are then compared to that of real-time experimental results. The results obtained showed good correlation between output and targets using ANNs.

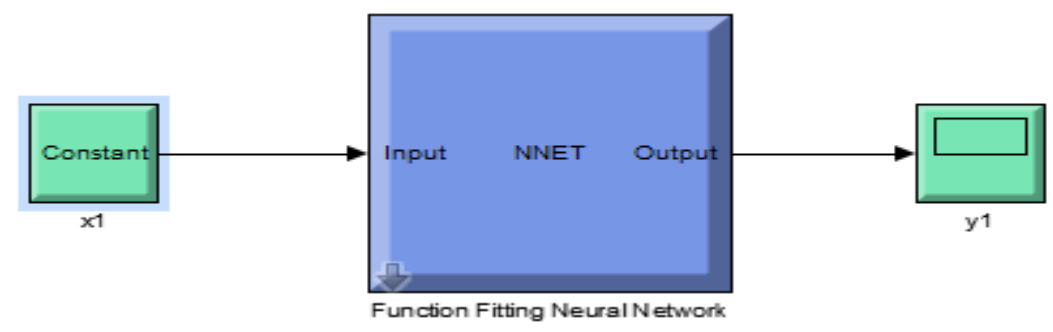

Fig.8. Simulink Model Developed after Training in ANN Toolbox

\section{Conclusion}

The paper successfully highlights a novel learning approach for data learning and prediction using ANNs. The study has considered Levenberg-Marquardt learning algorithm for training of neural networks. The proposed algorithm learns input-output characteristics of LVDT setup in an effective manner. The data pattern generated can be further used for prediction and estimation of output characteristics of LVDT for real-time applications. The values of MSE and regression showed excellent learning characteristics and need not to be further optimised. The training of ANNs has been completed using 10 neurons in the hidden layer and 1 neuron in the output layer. Finally, a Matlab based Simulink model has been developed which can be used for predicting the results LVDT in an effective manner. The output results verified the validity of proposed study.

\section{References}

[1] Yu D, Ham S, Park J, Yun S. (2011). Analysis and design of LVDT. In Proceedings of IEEE $8^{\text {th }}$ International Conference on Ubiquitous Robots and Ambient Intelligence (URAI), 23-26 Nov 2011, Incheon, South Korea, doi: 10.1109/URAI.2011.6146035.

[2] Masi A, Danisi A, Losito R, Mastino M, Spiezia G. (2010). Study of magnetic interference on a LVDT prototype. In Proceedings of IEEE International Conference on Instrumentation and Measurement Technology, 3-6 May 2010, Austin, USA, doi: 10.1109/IMTC.2010.5488091.

[3] Santhosh K.V., Roy B.K. (2012). An intelligent displacement technique using LVDT with an optimized ANN. Artificial Intelligent Systems and Machine learning, 4(8): 488-493.

[4] Joshi S, Harle S.M. (2017). Linear variable differential transducer (LVDT) \& its application in Civil Engineering. International Journal of Transportation Engineering and Technology, 3(4): 62-66, doi: 10.11648/ijet.20170304.13.

[5] Masi A, Danzeca S, Losito R, Peronnard S.R., Spiezia G. (2014). A high precision radiation-tolerant LVDT conditioning module. Nuclear Instruments and Methods in Physics, 745: 73-81, doi: 10.1016/j.nima.2014.01.054.

[6] Santhosh K.V., Roy B.K. (2012). A smart displacement measuring technique using Linear variable displacement transducer. Procedia Technology, 4(2012): 854-861, doi: 10.1016/j.protcy.2012.05.140.

[7] Liu Y.T., Kuo Y.L., Yan D.W. (2017). System integration for on-machine measurement using a capacitive LVDT-like contact sensor. Advances in Manufacturing, 5(1): 50-58, doi: 10.1007/s40436016-0169-y. 
[8] Meydan T, Healey G.W. (1992). Linear variable differential transformer (LVDT): linear displacement transducer utilizing ferromagnetic amorphous metallic glass ribbons. Sensors and Actuators, 32(1-3): 582-587, doi: 10.1016/0924-4247(92)80047-7.

[9] Tian G.Y., Zhao Z.X., Bainer R.W., Zhang N. (1997). Computational algorithms for linear variable differential transformers (LVDTs). IEE Proceedings-Science, Measurement and Technology, 144(4): 189-192, doi: 10.1049/ip-smt:19971262.

[10] Muhammad U.K., Umar S. (2013). Sensitivity determination of Linear variable differential transducer (LVDT) in fluid level detection techniques. International Journal of Modern Engineering Sciences, 2(2): 73-83.

[11] Anandan N., George B. (2017). Design and development of a planar linear variable differential transformer for displacement sensing. IEEE Sensors Journals, 17(16): 5298-5305, doi: 10.1109/JSEN.2017.271.9101.

[12] Suresh V., Ramu G. (2012). Real time measurement of position as well as direction using linear variable differential transformer. International Journal of Engineering Research and Applications, 2(3): 246-252.

[13] Uhrig R.E. (1995). Introduction to artificial neural networks. In Proceedings of 21st IEEE International Conference on Industrial Electronics, Control and Instrumentation (IECON), 6-10 Nov 1995, Orlando, USA, doi: 10.1109/IECON.1995.483329.

[14] Bose B.K. (2001). Neural network applications in power electronics and motor drives-An introduction and perspective. IEEE Transaction on Industrial Electronics, 54(1): 14-33, doi: 10.1109/TIE.2006.888683.

[15] Shi L., Wang X.C. (2010). Artificial neural networks: current applications in modern medicine. In Proceedings of IEEE International Conference on Computer and Communication Technologies in Agriculture Engineering (CCTAE), 12-13 June 2010, Chengdu, China, doi: 10.1109/CCTAE.2010.5543470.

[16] Bhuvaneswari S., \& Sabarathinam, J. (2013). Defect analysis using artificial neural network. International Journal of Intelligent Systems and Applications, 6(5): 33-38, doi: 10.5815/ijisa.2013.05.05.

[17] Al-Maqaleh B.M., Al-Mansoub A.A., \& Al-Badani F.N. (2016). Forecasting using Artificial neural network and statistics models. International Journal of Education and Management Engineering, 6(3): 20-32, doi:10.5815/ijeme.2016.03.03.

[18] Kumar K., \& Abhishek (2012). Artificial neural network for diagnosis of kidney stone disease. International Journal of Information Technology and Computer Science, 5(7): 20-25, doi: 10.5815/ijitcs.2012.07.03.

[19] Duranton M. (1996). Image processing by neural networks. IEEE Micro, 16(5): 12-19, doi: $10.1109 / 40.540076$.

[20] Baptista, D., \& Morgad-Dias, F. (2013). A Survey of artificial neural network training tools. Neural Computing and Applications. 23(3-4):609-615, doi: 10.1007/s00521-013-1408-9.

[21] Liu H, Cocea M. (2017). Semi-random partitioning of data into training and test sets in granular computing context. Granular Computing, 2(4): 357-386, doi: 10.1007/s41066-017-0049.

[22] Jayne C, Iliads L, Mladenov V. (2016). Special issue on the engineering applications of neural networks. Neural Computing and Applications. 27(5): 1075-1076, doi: 10.1007/s00521-016-2318-4.

[23] Zhao S.J., Xu Y.M. (2004). Levenberg-Marquardt algorithm for nonlinear principal component analysis neural network through inputs training. In Proceeding of IEEE Fifth World Congress on Intelligent Control and Automation, 15-19 June 2004, Hangzhou, China, doi: 10.1109/WCICA.2004.1343139.

[24] Dao-de S. (2000). Selection of the linear regression model according to the parameter estimation. Wuhan University Journal of Natural Science, 5(4): 400-405, doi: 10.1007.BF0285076. 


\section{Authors' Profiles}

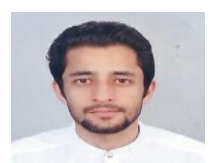

Mr. Ashwani Kharola received B.Tech (with Honors) in Mechanical Engineering from Dehradun Institute of Technology, Dehradun in 2010 and M.Tech in CAD/CAM \& Robotics from Graphic Era University, Dehradun in 2013. Presently he is working as Assistant Professor in Department of Mechanical Engineering at Tula's Institute, Dehradun. Earlier he has worked as a Research Fellow in Institute of Technology Management (ITM), One of premier training institute of Defence Research \& Development Organisation (DRDO), Ministry of Defence, Govt. of India. He is pursuing PhD in Mechanical Engineering from Graphic Era University (Deemed University), Dehradun. He has published many Research papers in National/International peer reviewed ISSN Journals and IEEE Conferences. His current areas of work includes Fuzzy logic reasoning, Adaptive Neuro-fuzzy inference system (ANFIS) control, Neural Networks, PID, Mathematical Modeling \& Simulation. He can be contacted at ashwani.kharola@tulas.edu.in

How to cite this paper: Ashwani Kharola,"Artificial Neural Networks based Approach for Predicting LVDT Output Characteristic", International Journal of Engineering and Manufacturing(IJEM), Vol.8, No.4, pp.21-28, 2018.DOI: 10.5815/ijem.2018.04.03 